\title{
The peculiarities of monitoring road vehicle per- formance and environmental impact
}

\author{
Ivan Kuric ${ }^{1}$, Vasyl Mateichyk ${ }^{2, *}$, Miroslaw Smieszek $^{2}$, Mykola Tsiuman $^{3}$, Nataliia Goridko $^{3}$ \\ and Igor Gritsuk ${ }^{4}$ \\ ${ }^{1}$ University of Zilina, Faculty of Mechanical Engineering, Department of Automation and Production \\ Systems, 01026 Zilina, Univerzitna 8215/1, Slovakia \\ ${ }^{2}$ Rzeszow University of Technology, Department of Quantitative Methods, 35-959 Rzeszow, al. \\ Powstancow Warszawy, 8, Poland \\ ${ }^{3}$ National Transport University, Faculty of Automotive and Mechanical Engineering, 01010 Kyiv, 1 \\ Omelianovycha-Pavlenka str., Ukraine \\ ${ }^{4}$ Kherson State Maritime Academy, Department of Operation of Ship Power Plants, 73000 Kherson, 20 \\ Ushakova avenue, Ukraine
}

\begin{abstract}
The article describes the peculiarities of mathematical models for determining the performance indicators of operation and environmental impact of road vehicles. The models are the basis of intelligent monitoring systems for separate road transport objects: vehicle propulsion systems, separate vehicles in motion on the real route and traffic flows. The structures of these monitoring systems with the characteristics of input data, the features of simulating the main processes and output results of monitoring the performance indicators of operation and environmental impact of road vehicles are presented. The examples of current parameters monitoring of the car with a gasoline engine in three typical motion phases in the traffic flow are given.
\end{abstract}

Keywords: road vehicle, mathematical model, monitoring system, performance indicators of operation, environmental impact

\section{Introduction}

Road vehicles are currently the most efficient means of passenger and freight transportation, individual trips, etc. At the same time, road vehicles are the largest consumers of fuel and other resources. They are the sources of noise, vibrations, electromagnetic radiation and environmental pollution by different solid and gaseous substances.

The issues of road vehicle performance have been important throughout the history of automobiles. With increasing number of automobiles, the issues of environmental impact of road transport have become more urgent.

Many scientists [1-10] devoted their research to environmental impact of road network objects - separate vehicles and traffic flows - and the ways to improve their environmental safety. The investigations also focused on the development of methods to study and predict environmental safety of separate vehicles and roadside pollution by traffic flows. The

\footnotetext{
* Corresponding author: vmate@prz.edu.pl

Reviewers: Kateryna Kravchenko, Dalibor Barta
} 
development of transport environmental monitoring systems was of great scientific interest as well.

The paper [1] is devoted to the study of environmental pollution by motor transport and methods for preventing such pollution. It results in the development of a "driver-vehicleroad-environment" system which enables to optimize the operation factors for reducing environmental pollution by motor transport.

The research [2] deserves particular attention. The research results include the systematized quantitative estimation of harmful emissions by different categories of vehicles, the estimation of urban environmental pollution by motor transport. Measures aimed at reducing air pollution by vehicles have also been analysed.

The issues of improving vehicle environmental safety are described in [7]. The research includes systems analysis methods for developing a mathematical model of "road vehicle" system. It enables to evaluate vehicle environmental safety and to find ways to improve it. The peculiarities of developing a mathematical model of "traffic flow-road" system and creating specific elements for intelligent monitoring system (IMS) of vehicle environmental safety in operation are described in $[8,9]$.

[10] describes the peculiarities of "Vehicle to Infrastructure" (V2I) information system and the process of monitoring and evaluating the vehicle technical condition in operation with the possibility of forecasting. The system is based on the general approach to investigate the "Vehicle - Driver - Operating Conditions - Vehicle Operation Infrastructure" system.

The issue of integrating IMS separate elements of vehicle environmental safety to monitor and control roadside pollution by traffic flows requires additional research.

The composition and the level of hardware and software for intelligent monitoring systems significantly depend on monitoring objects and monitoring tasks (Fig. 1). Vehicle propulsion systems, separate vehicles and traffic flows are considered to be monitoring objects in road transport. Depended on monitoring tasks intelligent monitoring systems can include monitoring systems of monitoring objects technical performance (such as the speed of motion, the mode of motion, operation process parameters, technical condition, traffic flow composition, etc) [11]. On the other hand, the monitoring systems of environmental performance are more science intensive because it significantly depends on both operational technical performance and design parameters of monitoring objects [12].

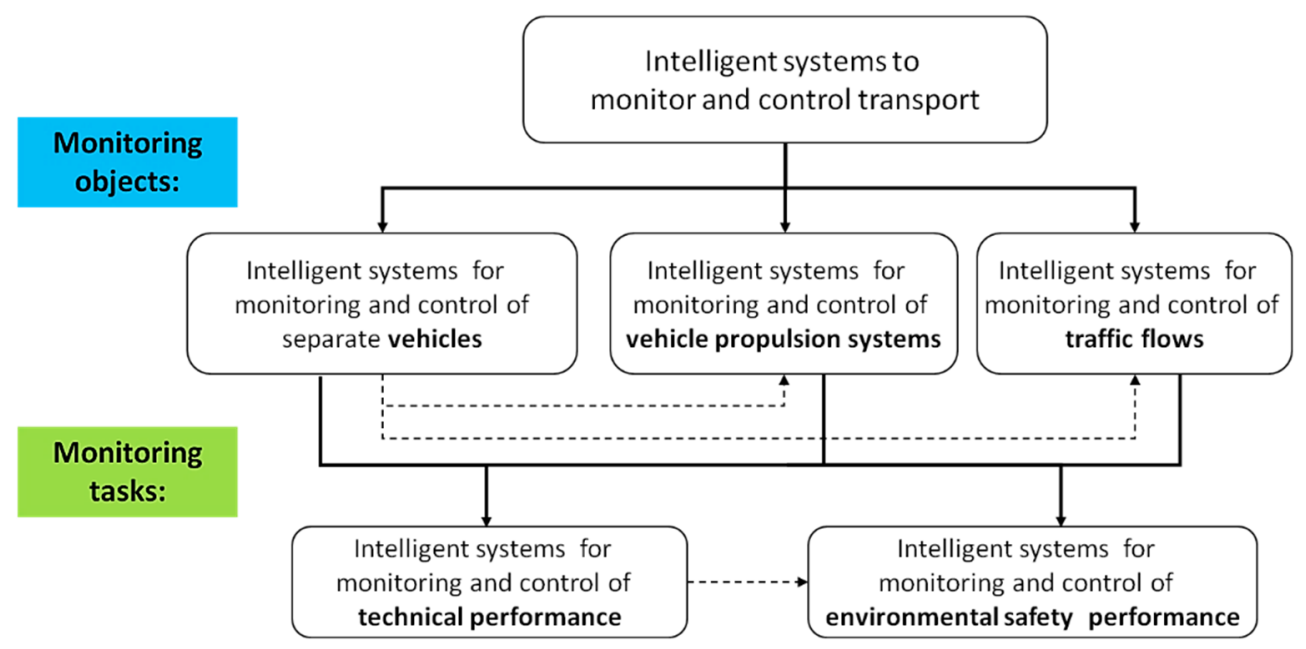

Fig. 1. The hierarchy of using intelligent monitoring systems in transport 


\section{The stages of vehicle monitoring process}

\subsection{Monitoring of vehicle propulsion system parameters}

The first stage of vehicle monitoring is vehicle performance evaluation for standard driving cycles. This enables to evaluate the efficiency of certain means for improving fuel economy and environmental performance of vehicle propulsion systems according to specific vehicle operation conditions. The mathematical model of the "engine-catalytic converter" system [13] is used for this purpose. The mathematical model is based on volume balance method [14]. The model enables to determine fuel economy, engine power and environmental performance according to its design parameters, operation mode, fuel type and environmental parameters. The input data for modeling are the actual engine operation data obtained from in-cylinder pressure sensor; engine parameters in steady operation modes obtained in laboratory experiments; on-board diagnostics (OBD) system data for appropriate modes of vehicle motion (Fig. 2). The data set of in-cylinder working body parameters, fuel economy, engine power and environmental performance in operation modes according to modes of vehicle motion in a driving cycle is determined during simulation. The vehicle fuel economy and environmental performance in the driving cycle are the simulation results.

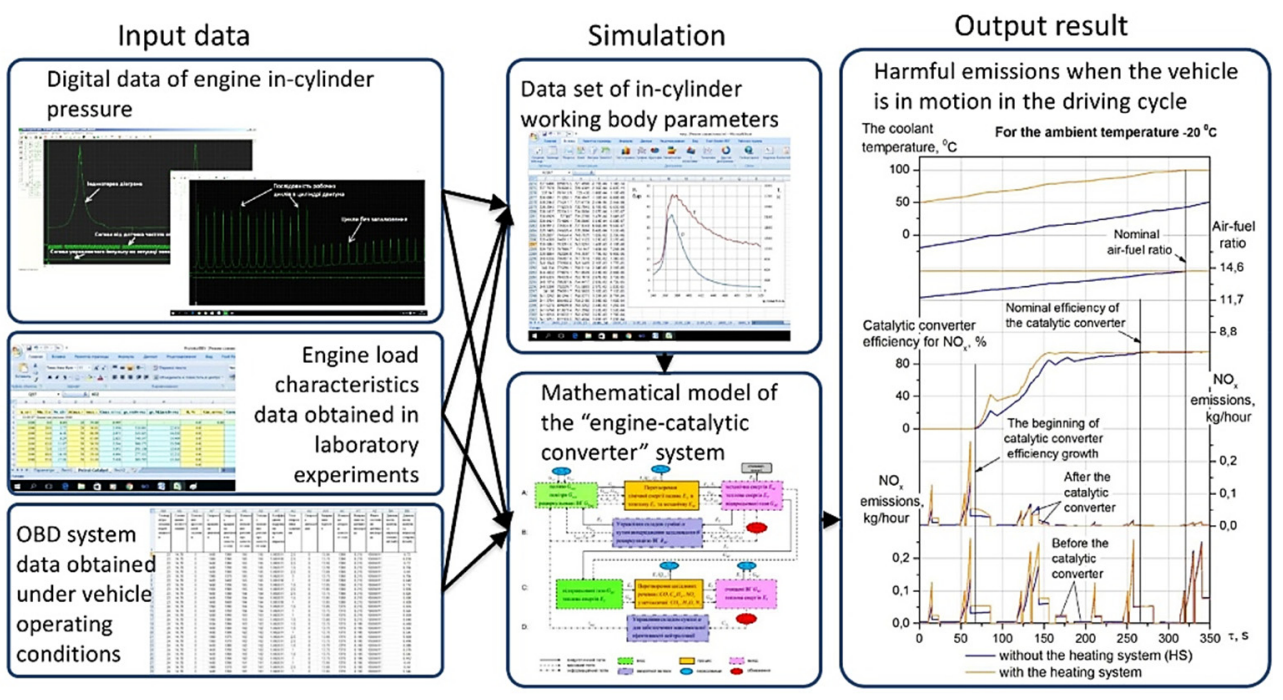

Fig. 2. Monitoring of vehicle propulsion system parameters

\subsection{Monitoring of vehicle parameters}

The second stage of vehicle monitoring is environmental safety evaluation when the vehicle is in motion on the real route. It is possible using OBD data and vehicle current location parameters based on Global Positioning System (GPS) data. Figure 3 shows the enlarged functional scheme of vehicle performance monitoring under operating conditions. The data set of real characteristics of the vehicle route is determined according to the vehicle current location data. This is the basis for determining real resistance forces of the vehicle motion on the route. Using the mathematical model of the "road vehicle" system [7], the environmental safety is evaluated when the vehicle is in motion on a certain route. The obtained data of vehicle motion parameters and environmental safety parameters are transferred to remote databases for further analysis using data transmission systems. 


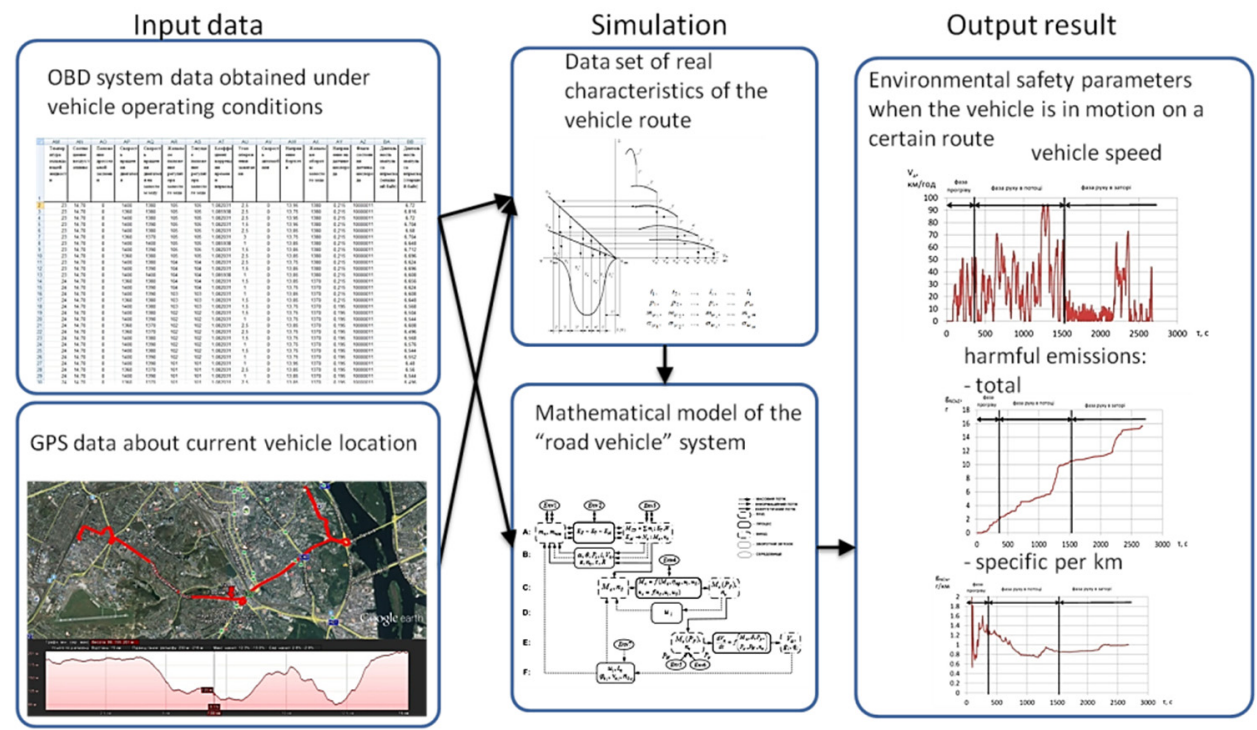

Fig. 3. Monitoring of vehicle parameters

\subsection{Monitoring roadside pollution by traffic flow}

Traffic flow parameters can be monitored and controlled according to the information from vehicle parameters database (Fig. 4). Thus, the traffic flow structure is created according to the vehicle categories, fuel types, vehicle environmental classes and traffic flow intensity. Route parameters and weather conditions are determined by the monitoring system according to the vehicle current location data. The simulation of vehicle environmental safety in the traffic flow and the evaluation of roadside pollution by the traffic flow are based on the determined traffic flow parameters. The use of geographical information systems (GIS) enables to visualize and analyze roadside pollution by traffic flows.

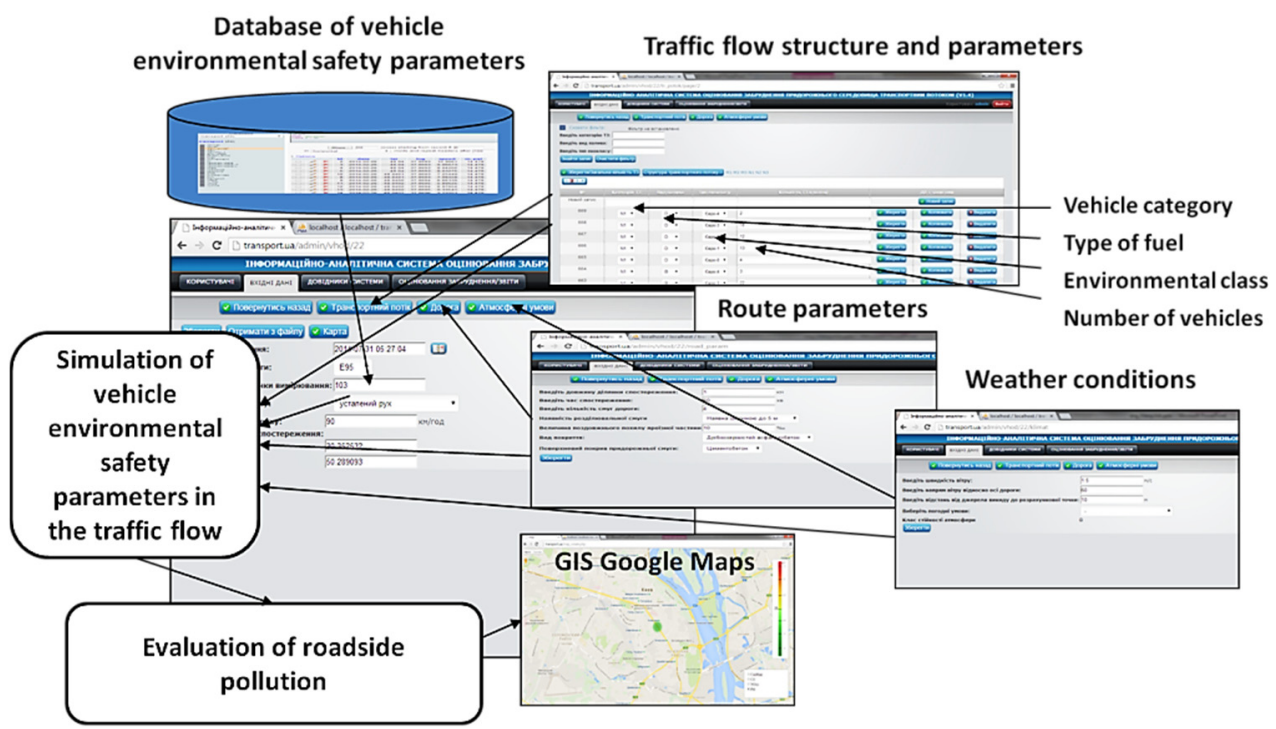

Fig. 4. Monitoring roadside pollution by traffic flow 


\section{The examples of vehicle monitoring results}

Fig. 5, 6 show the examples of current parameters of the car with a gasoline engine moving in the city traffic flow and a separate vehicle environmental safety.

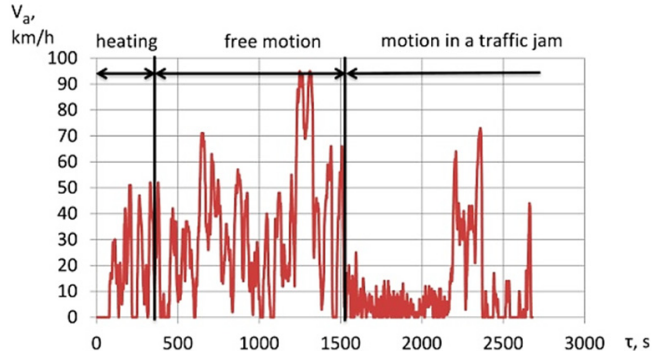

a)

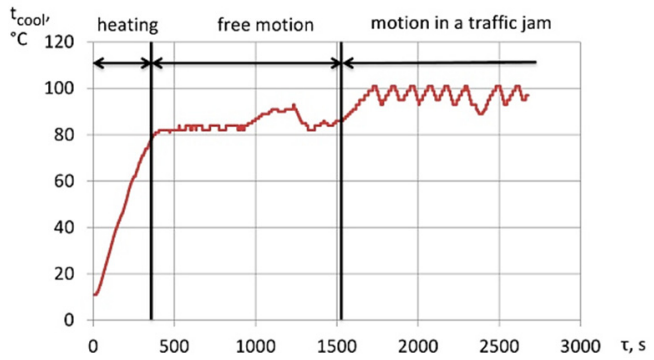

c)

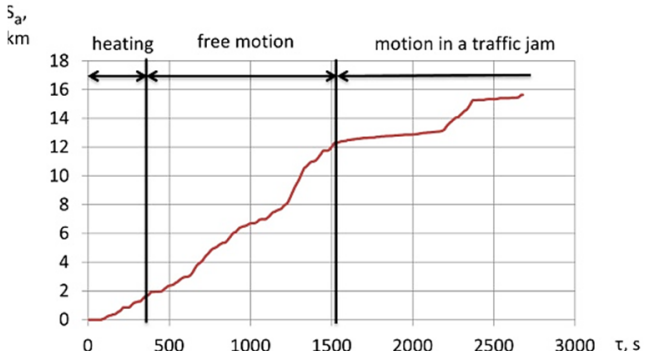

b)

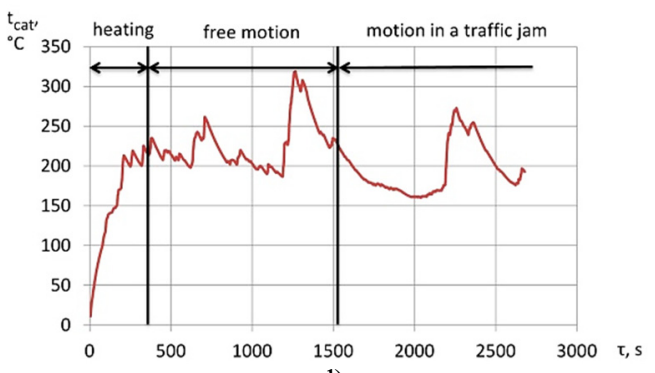

d)

Fig. 5. Vehicle motion parameters in the traffic flow: a) speed; b) the distance travelled; c) coolant temperature; d) catalytic converter temperature

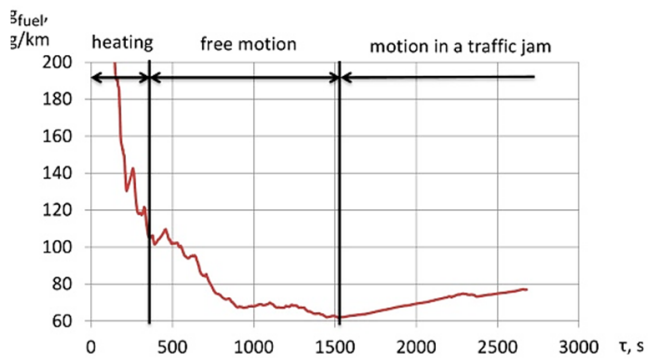

a)

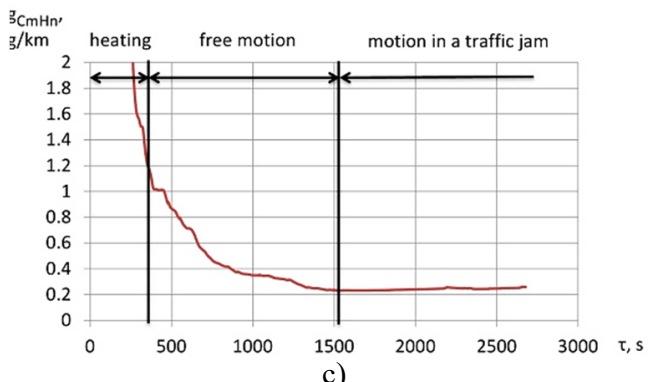

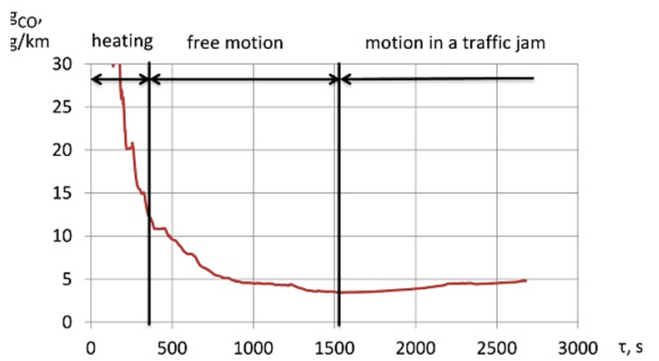

b)

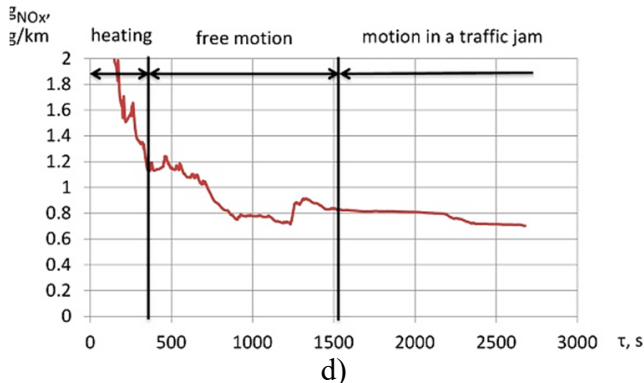

d)

Fig. 6. A separate vehicle environmental safety performance:

a) fuel consumption; b) $\mathrm{CO}$ emission; c) $\mathrm{C}_{\mathrm{m}} \mathrm{H}_{\mathrm{n}}$ emission; d) $\mathrm{NO}_{\mathrm{x}}$ emission 
The analysis of the obtained vehicle motion parameters (Fig. 5) enables to determine three typical motion phases, namely: heating, free motion and motion in a traffic jam. The heating phase is characterized by low speed of motion $V_{\mathrm{a}}$, increasing the coolant temperature $t_{\text {cool }}$ and catalytic converter temperature $t_{\text {cat }}$ to operating values, the increased values of specific fuel consumption $g_{\text {fuel }}$, carbon monoxide emission $g_{\mathrm{CO}}$, hydrocarbons emission $g_{\mathrm{CmHn}}$, nitrogen oxides emission $g_{\mathrm{NOx}}$ (Fig. 6).

The phase of free motion is characterized by increasing the speed mode (Fig. 5 a), increasing the distance travelled $S_{\mathrm{a}}$ (Fig. 5 b), normal values of the coolant temperature (Fig. $5 \mathrm{c}$ ) and catalytic converter temperature (Fig. 5 d). This contributes to the decreased values of specific fuel consumption and harmful emission (Fig. 6).

The temperature mode of the cooling system in the phase of motion in a traffic jam is characterized by maximum values of the coolant temperature and periodic turning on the radiator cooling fan (Fig. 5 c). In contrast, the temperature mode of the catalytic converter is characterized by the decreased temperature (Fig. $5 \mathrm{~d}$ ). This is related to low engine load. The values of specific fuel consumption and harmful emission increase in this phase (Fig. 6).

\section{Conclusion}

Thus, the approach to evaluate the efficiency of road vehicle operation and environmental impact is shown. The vehicle performance in standard driving cycles, based on fuel economy, power and environmental performance of the vehicle propulsion systems, is taken into account in this approach. It also implies the vehicle current location and motion parameters under real route conditions, total roadside pollution by the traffic flow according to the determined emissions of separate vehicles in traffic. The examples of current parameters monitoring of the car with a gasoline engine in three typical motion phases in the traffic flow are given. It is shown that the phases of heating and motion in a traffic jam are characterized by increased fuel consumption and, consequently, increased harmful emissions.

\section{References}

1. Yu.F. Gutarevych, Reducing vehicle emissions under operating conditions: Monograph. Vyshcha shkola, Kyiv, (1991)

2. V.N. Lukanin, Yu.V. Trofimenko, Environmental burden decrease in motor transport operation. The outcomes of science and technology. Ser. Automobile and city transport, VINITI, Moscow, (1996)

3. V.A. Zvonov, A.V. Kozlov, V.F. Kutenev, Environmental safety of a car in the complete life cycle. NAMI, Moscow, (2001)

4. P.M. Kanilo, Motor transport. Fuel and environmental problems and prospects: Monograph. KhNAHU, Kharkiv, (2013)

5. P. Eastwood, Particulate Emissions from Vehicles. John Wiley \& Sons Ltd, Chichester, (2008)

6. A. Faiz, C.S. Weaver, M.P. Walsh, Air Pollution from Motor Vehicles: Standards and Technologies for Controlling Emissions. The World Bank, Washington, D.C., (1996)

7. V.P. Mateichyk, Evaluation methods and methods for improving environmental safety of road vehicles: Monograph. NTU, Kyiv, (2006)

8. V.P. Mateichyk, M.P. Tsiuman, H.O. Waigang, Simulation of the "traffic flow - road" system. Inter-university collected articles "Scientific notes", 46, 371-381, (2014) 
9. V.P. Mateichyk, M.P. Tsiuman, Creating the structure of intelligent monitoring system for environmental safety indicators of vehicles at various stages of life cycle. The Herald of National Transport University, 32, 193-200, (2015)

10. I.V. Gritsuk, V. Volkov, V. Mateichyk, Yu. Grytsuk et al., Information Model of V2I System of the Vehicle Technical Condition Remote Monitoring and Control under Operating Conditions. SAE Technical Paper 2018-01-0024 (2018)

11. V.P. Volkov, P.B. Komov, O.B. Komov, I.V. Gritsuk, The peculiarities of transport and information monitoring system "KhNADU-TESA". Automobile and Electronics. Modern Technologies, 4, 106-110, (2013)

12. V.P. Mateichyk, H.O. Waigang, M. Smieszek, Information monitoring system of roadside pollution by traffic flows. Automobile and Electronics. Modern Technologies, 4, 74-77, (2013)

13. I. Gritsuk, V. Volkov, V. Mateichyk, Yu. Gutarevych, M. Tsiuman, N. Goridko, The Evaluation of Vehicle Fuel Consumption and Harmful Emission Using the Heating System in a Driving Cycle. SAE International Journal of Fuels and Lubricants, 10(1), doi:10.4271/2017-26-0364, (2017)

14. V.G. Diachenko, Internal combustion engines: Theory: Manual. NTU “KhPI”, Kharkiv, (2008) 